\title{
Are Radiology Technologists Satisfied with Their Work? A Cross-Sectional Study from Taif Hospitals
}

\author{
Sultan Alamri ${ }^{*}$, Nahla Faizo', Magbool Alelyani ${ }^{2}$, Ali Alghamdi ${ }^{3}$, Shahad Altwerqi', \\ Ghaida'a Almarghoub1, Nada Almalki', Shaima'a Almarghoub1, \\ Sarah Alzahrani ${ }^{1}$, Shahad Alhamami ${ }^{1}$
}

${ }^{1}$ Department of Radiological Sciences, College of Applied Medical Sciences, Taif University, Taif, Saudi Arabia ${ }^{2}$ Department of Radiological Sciences, College of Applied Medical Sciences, King Khaled University, Abha, Saudi Arabia ${ }^{3}$ Department of Radiological Sciences, College of Applied Medical Sciences, Tabuk University, Tabuk, Saudi Arabia Email: *s.alamri@tu.edu.sa

How to cite this paper: Alamri, S., Faizo, N., Alelyani, M., Alghamdi, A., Altwerqi, S., Almarghoub, G., Almalki, N., Almarghoub, S., Alzahrani, S. and Alhamami, S. (2020) Are Radiology Technologists Satisfied with Their Work? A Cross-Sectional Study from Taif Hospitals. Open Journal of Radiology, $10,45-56$

https://doi.org/10.4236/ojrad.2020.102006

Received: March 30, 2020

Accepted: May 6, 2020

Published: May 9, 2020

Copyright $\odot 2020$ by author(s) and Scientific Research Publishing Inc. This work is licensed under the Creative Commons Attribution International License (CC BY 4.0).

http://creativecommons.org/licenses/by/4.0/

\begin{abstract}
Background: Job satisfaction can affect workers' behaviour, thereby influencing organisational performance. Workers with low levels of job satisfaction have negative attitudes toward their jobs and may cause depression and anxiety. Purpose: The main aim of this study is to measure the overall job satisfaction among radiographers in Taif city. Methods: This study used the Minnesota Scoring Questionnaire to measure job satisfaction. The data collection was conducted between September 2018 and April 2019 in all major hospitals in Taif. Results: This study revealed that the overall job satisfaction of radiographers was moderate. It is, however, higher among radiographers in armed forces hospitals compared with their counterparts in the Ministry of Health hospitals. The job satisfaction of male radiographers was greater than their female peers. Finally, job satisfaction was high in those who work in advanced modality departments. Conclusion: Job satisfaction is critical for healthcare workers. This study indicated that job satisfaction is moderate for radiographers in Taif hospitals. Factors affecting their satisfaction include the feel of independence and recognition.
\end{abstract}

\section{Keywords}

Job Satisfaction, Radiological Worker, Taif Hospital, Radiology

\section{Introduction}

There are various definitions of job satisfaction from researchers and practitio- 
ners. Greenberg and Baron define job satisfaction as, "positive or negative attitudes held by individuals toward their job" [1]. On the other hand, Locke (1976) described it as, "the pleasure emotional state resulting from the appraisal of one's job as achieving or facilitating the achievement of one's job values". Several studies provide evidence that job satisfaction is related to productivity and performance [2] [3] [4].

Job satisfaction can also affect workers behaviour, thereby influencing organisational performance [5]. Regarding healthcare workers, studies report a connection between patient satisfaction and the job satisfaction of healthcare workers [6] [7]. Workers with higher levels of job satisfaction tend to exhibit a positive attitude toward their jobs, indicated by low withdrawal behaviour. In contrast, workers with low levels of job satisfaction have negative attitudes toward their jobs [8]. Furthermore, job satisfaction has been proven to elevate workers' physical health and mental abilities and enhance the atmosphere in an organisation [4] [9] [10].

Additionally, several studies reported that dissatisfaction can negatively influence worker's mental health and cause depression and anxiety [3]. A number of factors have been found to have potential effects on worker's mental health and wellbeing. These factors could result in an increased level of stress [11]. According to the literature, stress, depression, slowness, exhaustion, and carelessness are potential results of dissatisfaction in the workplace [12]. Dissatisfaction at work may also reduce organisational commitment and life satisfaction. It has also been connected to increased resignation, early retirement applications, and hostile behaviours at workplace [8]. Therefore, it is important to understand that job dissatisfaction can have serious consequences to a worker's wellbeing, the performance of an organisation, and consequently, customer satisfaction.

Many scholars studied the importance of workers' motivation in order to increase job satisfaction. Job satisfaction among healthcare workers is highly influenced by healthcare facility factors, such as financial matters, safety at work, style of management, and opportunities for professional advancement [13]. Other healthcare facility-related factors that may influence dissatisfaction include conditions where the workspace is overcrowded, noisy, dark, and has poor air quality [14].

Radiology department workers play a crucial role in healthcare. Thus, it is important to motivate the radiology department staff and monitor their job satisfaction levels to insure a highly functioning work environment. Few studies in the scientific literature focused on radiology technologists [2] [5] [15] [16] [17] [18] [19]. However, to date, there is no published work that assessed the issue of job satisfaction among radiology technologists in Saudi Arabia. Therefore, we bear a responsibility to act and assess the job satisfaction of radiology technologists in Taif hospitals.

\section{Subjects and Methods}

This cross-sectional study focused on the sample and procedure and ran from 
September 2018 to April 2019. This study measured job satisfaction of radiology technologists in three major hospitals in Taif city, and there were a total of 142 Saudi radiographers. This study does not require ethics approval because the study did not deal with a vulnerable group and does not involve any risk for the participant.

To measure job satisfaction, this study used the Minnesota Satisfaction Questionnaire (MSQ) [20], and the statistical tests of the questionnaire data were performed using the Statistical Package for the Social Science (SPSS). The questionnaire consisted of two parts. The first part is related to the social demographic data that contained gender, age, qualifications, years of experience, the institution where the participant works, and any subspecialty. The second part consisted of 20 questions about job satisfaction which included questions related to activity, independence, variety, social status, supervision, moral values, security, social services, authority, utilisation ability, company policies and practices, compensation, advancement, responsibility, creativity, working conditions, co-workers, recognition, and achievement. The participants were asked to answer each question individually and had to choose one of the following options: (very satisfied, satisfied, neutral, dissatisfied, or very dissatisfied).

We began with a pilot study that was comprised of four participants (two participants from the King Abdul-Aziz Specialist Hospital [KASH] and two from the King Faisal Medical Complex). Based on this pilot study, we adjusted our questionnaire to ensure the participants understood the questions. The data was collected from the radiographers in the radiology department in both the armed forces hospitals (Alhada, prince Mansour and prince Sultan hospitals) and Ministry of Health hospitals (the King Abdul-Aziz Specialist Hospital, the King Faisal Medical Complex, the children hospital). Furthermore, to make the data more homogenous, the variables were divided and grouped into two categories. Age was divided into two groups (older than or younger than 30 years old). In addition, qualifications were divided into two groups (diploma and higher). Moreover, experience was divided into two categories (greater than and less than five years). For the subspecialty, it was divided into general radiology (GR) (i.e., a traditional $\mathrm{x}$-ray department) and advanced modalities, including computed tomography (CT), magnetic resonance imaging (MRI), ultrasound (U/S), nuclear medicine, radiation therapy, and intervention radiology. A score of $75 \%$ or more was considered to reflect a high degree of satisfaction, while a score of lower than $25 \%$ represented a low degree of satisfaction. A moderate degree of satisfaction was represented by scores between $25 \%$ and $75 \%$.

After data collection and division, the data were analysed using an SPSS programme. Significance levels were set at 5\% using the Pearson Chi-Square Test to assess the correlation between participant variables and each measured domain in the questionnaire. The Chi-Square test was chosen due to its ability to represent the categorical analysis. 


\section{Results}

The demographic variables of the participants are presented in Table 1 . There were slightly more men ( 86 or $60.6 \%$ ) than women (56 or $39.4 \%$ ). Of the 142 respondents, $49.3 \%$ were aged less than 30 years (between 20 and 30 years old) and $50.7 \%$ were older than 30 years (between 31 and 40 years old). Forty-four-pointfour percent of the respondents had a diploma, whereas $47.9 \%$ of the participants had a bachelor's degree. In addition, the majority of the participants (30.3\%) had between 5 to 10 years' experience. Moreover, $64.1 \%$ of the participants work for the Ministry of Health hospitals compared with 35.9\% who work in the armed forces hospitals. Of the 142 participants, $42.3 \%$ work in the general radiology department, whereas $19.7 \%$ and $14.8 \%$ work in the departments of CT and MRI, respectively.

We looked first at the level of satisfaction in relation to independence. Using the Minnesota scoring as presented in Table 2, we found that the overall satisfaction

Table 1. Demographic characteristics of participants.

\begin{tabular}{|c|c|c|c|}
\hline Items & Information & No. & $\%$ \\
\hline \multirow[t]{2}{*}{ Gender } & Male & 86 & 60.6 \\
\hline & Female & 56 & 39.4 \\
\hline \multirow[t]{4}{*}{ Age } & $22-30$ & 70 & 49.3 \\
\hline & $31-40$ & 65 & 45.8 \\
\hline & $41-50$ & 7 & 4.9 \\
\hline & $51-60$ & 0 & 0 \\
\hline \multirow[t]{4}{*}{ Qualification } & Diploma & 63 & 44.4 \\
\hline & Bachelor & 68 & 47.9 \\
\hline & Master & 10 & 7 \\
\hline & Ph.D. & 1 & 0.7 \\
\hline \multirow[t]{4}{*}{ Vocational experience } & $<3$ years & 31 & 21.8 \\
\hline & 3 - 5 years & 31 & 21.8 \\
\hline & 5 - 10 years & 43 & 30.3 \\
\hline & $>10$ years & 37 & 26.1 \\
\hline \multirow[t]{2}{*}{ Institution } & Ministry of Health & 91 & 64.1 \\
\hline & Armed Forces & 51 & 35.9 \\
\hline \multirow[t]{7}{*}{ Specialty } & General Radiography & 60 & 42.3 \\
\hline & CT & 28 & 19.7 \\
\hline & MRI & 21 & 14.8 \\
\hline & US & 12 & 8.5 \\
\hline & Nuclear Medicine & 11 & 7.7 \\
\hline & Radiotherapy & 6 & 4.2 \\
\hline & Interventional & 4 & 2.8 \\
\hline
\end{tabular}


Table 2. Minnesota satisfaction questionnaire (MSQ) results.

\begin{tabular}{|c|c|}
\hline Items & Satisfaction (\%) \\
\hline Activity & 81.1 \\
\hline Independence & 73.9 \\
\hline Variety & 76.6 \\
\hline Social Status & 86.6 \\
\hline Supervision-Human Relation & 65.6 \\
\hline Supervision-Technical & 66.7 \\
\hline Moral Values & 83.2 \\
\hline Security & 81.4 \\
\hline Social Services & 85.2 \\
\hline Authority & 83 \\
\hline Ability Utilisation & 86.1 \\
\hline Company Policies and Practices & 67.1 \\
\hline Compensation & 80.5 \\
\hline Advancement & 73.8 \\
\hline Responsibility & 70.7 \\
\hline Creativity & 74.7 \\
\hline Working Conditions & 70 \\
\hline Co-workers & 70.8 \\
\hline Recognition & 63.8 \\
\hline Achievement & 84.5 \\
\hline General Satisfaction & 76.3 \\
\hline
\end{tabular}

of radiographers is moderate $(73.9 \%)$. To investigate that more, the statistical analysis showed that radiographers in advanced modalities are more satisfied compared with their peers in conventional radiography (odds ratio (OR): 0.367 , $95 \%$ confidence interval $(\mathrm{CI}): 0.18$ to $0.74, \mathrm{p}=0.004)$. Moreover, radiographers in armed forces hospitals were more satisfied when compared with those in the Ministry of Health hospitals (OR: 0.45, 95\% CI: 0.215 to $0.97, \mathrm{p}=0.029$ ).

With regard to the satisfaction of radiographers on the way their superiors treat them, only $65.6 \%$ were satisfied, as presented in Table 2. The statistical analysis revealed a significant difference in satisfaction between radiographers in advanced modalities in contrast with general radiography (OR: 0.31, 95\% CI: 0.176 to $0.699, \mathrm{p}=0.002$ ). In addition, we found that the radiographers in the armed forces hospitals are more satisfied than radiographers in the Ministry of Health hospitals (OR: 0.511, 95\% CI: 0.215 to $1.042, \mathrm{p}=0.046$ ). Moreover, radiographers who had a bachelor's or higher degree were more satisfied compared with their peers who had a diploma, (OR: $0.468,95 \%$ CI: 0.238 to $0.921, \mathrm{p}=0.021$ ).

Regarding the satisfaction of radiographers with their superiors and their ability in making decisions, we found that overall satisfaction is moderate (66.7\%), 
as presented in Table 2 . The statistical analysis showed that male radiographers are more satisfied than females (OR: $2.820,95 \% \mathrm{CI}: 1.407$ to $5.652, \mathrm{p}=0.002$ ). In addition, radiographers older than 30 years were more satisfied than their younger counterparts (OR: $0.534,95 \% \mathrm{CI}: 0.273$ to $1.045, \mathrm{p}=0.047$ ). Moreover, radiographers in the advanced modalities were more satisfied than those working in conventional radiography (OR: $0.397,95 \% \mathrm{CI}: 0.200$ to $0.787, \mathrm{p}=0.006$ ).

When the participants were asked about their satisfaction in regard to the policies and practices of the institution in which they work, $67.1 \%$ of them were satisfied. The statistical analysis demonstrated that the radiographers who had less than 5 years' experience were more satisfied compared with those with more than 5 years (OR: 3.046, 95\% CI: 1.526 to $6.081, \mathrm{p}=0.001$ ). The most striking result was that the armed forces radiographers were more satisfied than Ministry of Health radiographers (OR: $0.278,95 \% \mathrm{CI}$ : 0.135 to $0.570, \mathrm{p}<0.001$ ). In addition, radiographers in the advanced modalities were more satisfied than radiographers working in conventional radiography, (OR: $0.500,95 \% \mathrm{CI}: 0.251$ to 0.996, $\mathrm{p}=0.035)$.

When asked about their satisfaction on the career advancement, the participants responded that their overall satisfaction was moderate $(73.8 \%)$. The statistical analysis showed no significant difference in satisfaction regarding gender, age, qualifications, vocational experience, institution, or specialty $(\mathrm{p}>0.05)$. What is most striking is that, while overall satisfaction in regard to creativity was high $(74.7 \%)$, there was no significant correlation between this question and any of the demographic variables $(\mathrm{p}>0.05)$.

Moreover, when the participants were asked about their satisfaction on their responsibilities as radiographers, the overall satisfaction was moderate $(70.7 \%)$. The statistical analysis showed that male radiographers are significantly more satisfied compared with females, (OR: $2.304,95 \% \mathrm{CI}: 1.159$ to $4.582, \mathrm{p}=0.013$ ). Further analysis of the data showed that satisfaction was much more strongly associated with radiographers older than 30 years compared with their younger peers, (OR: $0.536,95 \% \mathrm{CI}: 0.275$ to $1.045, \mathrm{p}=0.047$ ).

On the other hand, when the participants were asked about their satisfaction on working conditions, overall satisfaction was moderate (70\%). The statistical findings showed that the radiographers who were working in advanced modalities had significantly higher satisfaction compared with radiographers in general radiography (OR: $0.207,95 \% \mathrm{CI}: 0.101$ to $0.424, \mathrm{p}=0.001$ ). Furthermore, armed forces radiographers were more satisfied compared with Ministry of Health radiographers (OR: $0.468,95 \% \mathrm{CI}: 0.230$ to $0.955, \mathrm{p}=0.026$ ).

When the participants were asked about their satisfaction on their co-workers, overall satisfaction was moderate $(70.8 \%)$. The statistical findings showed the armed forces radiographers are more satisfied than their peers in the Ministry of Health (OR: $0.390,95 \%$ CI: 0.188 to $0.809, \mathrm{p}=0.008$ ).

Finally, when the participants were asked about their satisfaction on recognition they receive, overall satisfaction was moderate (63.8\%). Our statistical analyses 
revealed that advanced modality radiographers are more satisfied than those in conventional radiography (OR: $0.506,95 \%$ CI: 0.257 to $0.994, p=0.034$ ). Similarly, radiographers in armed forces hospitals were more satisfied with regard to recognition compared with radiographers at the Ministry of Health (OR: 0.487, 95\% CI: 0.241 to $0.982, \mathrm{p}=0.032$ ).

\section{Discussion}

Satisfaction on the job is a crucial aspect of any organisation's functionality. Nevertheless, it is a complicated subject that results from a variety of factors that have different meanings and interpretations from one employee to the other. Job satisfaction can significantly affect work quality, especially among healthcare workers due to the psychological dependence of their job. However, to the best of our knowledge, job satisfaction among radiology radiographers had not previously been evaluated in Saudi Arabia. Thus, this is the first study conducted to discuss the issue of job satisfaction in radiology departments in Saudi Arabia.

Based on a five-grade scale from "very satisfied" to "very unsatisfied", the findings point out an average job satisfaction score of $76 \%$. Moreover, $76.3 \%$ of radiographers are extremely or somewhat satisfied with their jobs. In addition, radiographers at armed forces hospitals are likely to feel greater job satisfaction than their peers at Ministry of Health hospitals in Taif city.

The concept of job satisfaction among radiology workers has been an area of research around the world. A study in the UK conducted by Hutton and his colleagues found that $36 \%$ of their research sample were classified satisfied, while $11 \%$ were dissatisfied, and the rest of the sample (53\%) had mixed feelings regarding job satisfaction [5]. In Sudan, it was reported that $63.3 \%$ of the participants were satisfied, while $29.5 \%$ were dissatisfied [21]. Moreover, a cross-sectional survey with 530 participants from Iran found more than half of the sample (53.5\%) was dissatisfied with their jobs [22].

Age is one of the factors affecting job satisfaction among radiographers. Our study showed that radiographers older than 30 years of age were more satisfied with their job. This outcome is contrary to that of a Lithuanian study which showed that younger radiographers were more satisfied with supervision and relationships with co-workers [23].

Education is another consideration that may influence worker satisfaction. This study's results corroborate the survey in Lithuania, which indicated that radiographers with a low degree of education (diploma) were less satisfied with respect to their supervisors. In addition, similar to this study, the results indicate that job satisfaction varies with the amount of work experience [23].

In a study conducted in the United States, workers of advanced radiology modalities reported that they were satisfied with their co-workers and their supervisors [18]. These findings are consistent with this study's findings. Radiographers in the advanced modalities at Taif hospitals were more satisfied with their co-workers and supervisors than radiographers of general imaging modali- 
ties. In addition, our study points out that radiographers of advanced modalities are satisfied with their income. However, that is not the case with radiographers of advanced modalities in the United States study [18].

Another important finding was that $70 \%$ of radiology department radiographers in Taif city hospitals are satisfied with their working conditions. This percentage is not dramatically different from an Italian study that was conducted in Torino University that showed that around $80 \%$ of the sample were satisfied with their working conditions, such as the organisation of shifts and the working environment [17]. Furthermore, the Torino study had similar results to this study regarding how working in advance modalities increases the level of satisfaction toward working conditions [17].

Finally, the results here showed that radiographers with more than 5 years' experience were more satisfied with their relationships with their supervisors and co-workers and their salary. This result contradicts the Italian study [17], which demonstrated that radiographers with more than 5 years of experience were less satisfied with the relationships with their supervisors and co-workers and their salary.

\section{Limitation}

Since this study was limited to measuring the level of job satisfaction among radiographers in Taif, it was not possible to identify the factors affecting it. In addition, to our knowledge, this is the first study looking at the level of job satisfaction among radiographers in Saudi Arabia and thus limited comparisons were made with the existing limited literature.

\section{Conclusion}

Job satisfaction is an important issue for optimal job productivity. It is influenced by multiple elements. This study aims to assess the job satisfaction of radiographers in Taif based on the results of an MSQ. Our research shows that job satisfaction among radiographers is higher among armed forces radiographers, males, and radiographers in advanced modalities. As this research is likely the first of its kind applied to radiology employees in Taif, we support this type of study to determine the level of job satisfaction among radiographers to improve their job productivity.

\section{Public significance Statement}

There is a connection between healthcare professionals' satisfaction and patient satisfaction. Workers tend to have positive behaviour if they have high level of job satisfaction and that would be directly reflected to patients.

\section{Conflicts of Interest}

The authors declare no conflicts of interest regarding the publication of this paper. 


\section{References}

[1] Kamarulzaman, W. and Nordin, M.S. (2012) Job Satisfaction: The Comparison between School-Leavers and College Graduates.

[2] Eslick, G.D. and Raj, V.V. (2000) Occupational Stress amongst Australian Radiographers: Prevalence, Risk Factors, Job Satisfaction and Impact. The Official Journal of the Australian Institute of Radiography, 47, 129.

[3] Faragher, E.B., Cass, M. and Cooper, C.L. (2005) The Relationship between Job Satisfaction and Health: A Meta-Analysis. Occupational and Environmental Medicine, 62, 105-112. https://doi.org/10.1136/oem.2002.006734

[4] Franco, L.M., Bennett, S. and Kanfer, R. (2002) Health Sector Reform and Public Sector Health Worker Motivation: A Conceptual Framework. Social Science \& Medicine, 54, 1255-1266. https://doi.org/10.1016/S0277-9536(01)00094-6

[5] Hutton, D., Beardmore, C., Patel, I., Massey, J., Wong, H. and Probst, H. (2014) Audit of the Job Satisfaction Levels of the UK Radiography and Physics Workforce in UK Radiotherapy Centres 2012. The British Journal of Radiology, 87, Article ID: 20130742. https://doi.org/10.1259/bjr.20130742

[6] Deshkulkarni, S. (2009) Perceptions of Interprofessional Communication: Causes and Effects on Patient Care, Occupational Stress, and Job Satisfaction. Electronic Theses and Dissertations.

[7] Haas, J.S., Cook, E.F., Puopolo, A.L., Burstin, H.R., Cleary, P.D. and Brennan, T.A. (2000) Is the Professional Satisfaction of General Internists Associated with Patient Satisfaction? Journal of General Internal Medicine, 15, 122-128. https://doi.org/10.1046/j.1525-1497.2000.02219.x

[8] Judge, T.A., Thoresen, C.J., Bono, J.E. and Patton, G.K. (2001) The Job Satisfaction-Job Performance Relationship: A Qualitative and Quantitative Review. Psychological Bulletin, 127, 376-407. https://doi.org/10.1037/0033-2909.127.3.376

[9] Ali Jadoo, S.A., Aljunid, S.M., Dastan, I., Tawfeeq, R.S., Mustafa, M.A., Ganasegeran, K., et al. (2015) Job Satisfaction and Turnover Intention among Iraqi Doctors: A Descriptive Cross-Sectional Multicentre Study. Human Resources for Health, 13, 21. https://doi.org/10.1186/s12960-015-0014-6

[10] Hackman, J.R. and Oldham, G.R. (1976) Motivation through the Design of Work: Test of a Theory. Organizational Behavior and Human Performance, 16, 250-279. https://doi.org/10.1016/0030-5073(76)90016-7

[11] Cooper, C.L., Rout, U. and Faragher, B. (1989) Mental Health, Job Satisfaction, and Job Stress among General Practitioners. BMJ, 298, 366-370.

https://doi.org/10.1136/bmj.298.6670.366

[12] Li, L., Hu, H., Zhou, H., He, C., Fan, L., Liu, X., et al. (2014) Work Stress, Work Motivation and Their Effects on Job Satisfaction in Community Health Workers: A Cross-Sectional Survey in China. BMJ Open, 4, e004897. https://doi.org/10.1136/bmjopen-2014-004897

[13] Wang, L., Tao, H., Ellenbecker, C.H. and Liu, X. (2012) Job Satisfaction, Occupational Commitment and Intent to Stay among Chinese Nurses: A Cross-Sectional Questionnaire Survey. Journal of Advanced Nursing, 68, 539-549. https://doi.org/10.1111/j.1365-2648.2011.05755.x

[14] Hung, L.-M., Shi, L., Wang, H., Nie, X. and Meng, Q. (2013) Chinese Primary Care Providers and Motivating Factors on Performance. Family Practice, 30, 576-586. https://doi.org/10.1093/fampra/cmt026

[15] Akroyd, H.D. and Shewchuk, R.M. (1990) Factors Related to Job Satisfaction of Ra- 
diographers. Radiologic Technology, 61, 472-477.

[16] Buddeberg-Fischer, B., Christen, S., Weishaupt, D., Hoffmann, A. and Kubik-Huch, R.A. (2011) Professional Satisfaction of Radiologists in Switzerland. Swiss Medical Weekly, 141, w13271. https://doi.org/10.4414/smw.2011.13271

[17] Gualano, M.R., Gili, R., Bert, F., Scaioli, G., Cerutti, S., Gatti, G., et al. (2016) Job Satisfaction among Radiology Assistants: A Multicentre Cross-Sectional Study in Italy. La Medicina del Lavoro, 107, 37-46.

[18] Knight, A. (2004) Nuclear Medicine Technologist Job Satisfaction. Journal of Nuclear Medicine Technology, 32, 220-228.

[19] Probst, H. and Griffiths, S. (2009) Job Satisfaction of Therapy Radiographers in the UK: Results of a Phase I Qualitative Study. Radiography, 15, 146-157. https://doi.org/10.1016/j.radi.2008.02.003

[20] Weiss, D.J., Dawis, R.V. and England, G.W. (1967) Manual for the Minnesota Satisfaction Questionnaire. Minnesota Studies in Vocational Rehabilitation.

[21] Elkhadir, A.M. and Saeed, I.O. (2018) Job Satisfaction of Radiographic Technologist in Sudan and the Main Reasons of Dissatisfaction. International Journal of Science and Research, 7, 12-14.

[22] Alavi, S.S., Dabbagh, S.T., Abbasi, M. and Mehrdad, R. (2017) Job Satisfaction and Its Relationship to Radiation Protection Knowledge, Attitude and Practice (RPKAP) of Iranian Radiation Workers. Eastern Mediterranean Health Journal, 22, 727-734. https://doi.org/10.26719/2016.22.10.727

[23] Vanckavičienè, A., Navickienè, R., Viliušienè, I. and Sakalauskienė, Z. (2017) Radiographers' Job Satisfaction: Cross-Sectional Survey in Lithuania. Radiology Update, 1, 30-37. 


\section{Appendix:}

\section{Job Satisfaction Questionnaire}

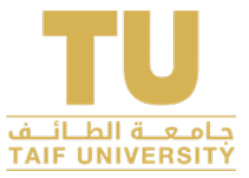

The purpose of this questionnaire is to give you a chance to tell how you feel about your present job, what things you are satisfied with and what things you are not satisfied with.

On the basis of your answers and those of people like you, we hope to get a better understanding of the things people like and dislike about their jobs.

On the next page, you will find statements about your present job.

- Read each statement carefully.

- Decide how satisfied you feel about the aspect of your job described by the statement.

Keeping the statement in mind:

- If you feel that your job gives you more than you expected, check the box under "Very Sat." (Very Satisfied);

- If you feel that your job gives you what you expected, check the box under "Sat." (Satisfied);

- If you cannot make up your mind whether or not the job gives you what you expected, check the box under "N" (Neither Satisfied nor Dissatisfied);

- If you feel that your job gives you less than you expected, check the box under "Dissat." (Dissatisfied);

- If you feel that your job gives you much less than you expected, check the box under "Very Dissat." (Very Dissatisfied).

- Remember: Keep the statement in mind when deciding how satisfied you feel about that aspect of your job.

- Do this for all statements. Please answer every item.

Be frank and honest. Give a true picture of your feelings about your present job.

\section{Part 1:}

\begin{tabular}{lcccc}
\hline A. Gender & Male & Female & & \\
B. Age & $22-30$ & $31-40$ & $41-50$ & $51-60$ \\
C. Qualification & Diploma & Bachelor & Master & Ph.D. \\
D. Vocational Experience (years) & $<3$ & $3-5$ & $5-10$ & $>10$ \\
E. Speciality & General x-ray & & \\
& CT & & \\
& MRI & & \\
& U/S & \\
& Nuclear Medicine \\
& Radiotherapy & \\
Interventional & \\
&
\end{tabular}




\section{Part 2:}

Ask yourself: How satisfied am I with this aspect of my job?

Very Sat. means I am very satisfied with this aspect of my job.

Sat. means I am satisfied with this aspect of my job.

$\mathrm{N}$ means I can't decide whether I am satisfied or not with this aspect of my job.

Dissat. means I am dissatisfied with this aspect of my job.

Very Dissat. means I am very dissatisfied with this aspect of my job.

\begin{tabular}{|c|c|c|c|c|c|c|}
\hline & On my present job, this is how I feel about .... & $\begin{array}{c}\text { Very } \\
\text { dissat. }\end{array}$ & Dissat. & $\mathrm{N}$ & Sat. & $\begin{array}{c}\text { Very } \\
\text { sat. }\end{array}$ \\
\hline 1. & Being able to keep busy all the time. & ○ & $\circ$ & $\circ$ & $\circ$ & $\circ$ \\
\hline 2. & The chance to work alone on the job. & ○ & $\circ$ & $\circ$ & $\circ$ & ० \\
\hline 3. & The chance to do different things from time to time. & ○ & $\circ$ & $\circ$ & $\circ$ & ○ \\
\hline 4. & The chance to be "somebody" in the community. & ○ & $\circ$ & $\circ$ & $\circ$ & ○ \\
\hline 5. & The way my boss handles his/her workers. & o & ○ & $\circ$ & o & o \\
\hline 6. & The competence of my supervisor in making decisions. & ० & ○ & $\circ$ & $\circ$ & ○ \\
\hline 7. & Being able to do things that don't go against my conscience. & ० & ○ & $\circ$ & ० & ○ \\
\hline 8. & The way my job provides for steady employment. & ० & ० & $\circ$ & $\circ$ & o \\
\hline 9. & The chance to do things for other people. & o & $\circ$ & $\circ$ & ० & ० \\
\hline 10. & The chance to tell people what to do. & ○ & ○ & $\circ$ & $\circ$ & ○ \\
\hline 11. & The chance to do something that makes use of my abilities. & ○ & $\circ$ & $\circ$ & $\circ$ & o \\
\hline 12. & The way company/institution policies are put into practice. & ○ & $\circ$ & $\circ$ & ○ & o \\
\hline 13. & My pay and the amount of work I do. & ○ & $\circ$ & $\circ$ & $\circ$ & ० \\
\hline 14. & The chances for advancement on this job. & o & $\circ$ & $\circ$ & o & ○ \\
\hline 15. & The freedom to use my own judgement. & ० & ○ & $\circ$ & $\circ$ & o \\
\hline 16. & The chance to try my own methods of doing the job. & ○ & $\circ$ & $\circ$ & $\circ$ & ○ \\
\hline 17. & The working conditions. & o & $\circ$ & $\circ$ & ○ & ○ \\
\hline 18. & The way my co-workers get along with each other. & o & $\circ$ & $\circ$ & ○ & ○ \\
\hline 19. & The praise I get for doing a good job. & ○ & ○ & $\circ$ & $\circ$ & $\circ$ \\
\hline 20. & The feeling of accomplishment I get from the job. & 0 & 0 & 0 & 0 & 0 \\
\hline
\end{tabular}

